\title{
Energy and Raw Materials - The Contributions of Chemistry and Biochemistry in the Future
}

\author{
Organized by the Swiss Chemical Society \\ Halle 1, Saal 'Luzern' - entrance free
}

The Swiss Chemical Society (SCS) is the founder and strategic partner of the ILMAC, the Industry Exhibition for Research and Development, Environmental and Process Technology in Pharmaceuticals, Chemicals and Biotechnology.

The SCS is proud to present a highly attractive program for this year's Scientific Forum at ILMAC:

\section{Energy and Raw Materials - The Contributions of Chemistry and Biochemistry in the Future}

In the coming decades the energy demand both in Switzerland and the rest of the world will increase. The objective of the Forum is to show how chemistry, as an interdisciplinary science, can make an important contribution to resolving key future issues in combination with other disciplines, commerce and industry.

Leading experts from Switzerland and abroad will give an overview of alternative energy resources and primary materials that are presently available for the chemical and pharmaceuticals industries.

The Forum will be split in four morning sessions each concluded by a panel discussion. There will be ample opportunity for the participants to ask questions.

Members of the Swiss Chemical Society will be offered free tickets for the ILMAC Exhibition at the desk of the Swiss Chemical Society at the entrance to Hall 1 or online (see page 550).

Tuesday, September 25, 2007 | 9.30-12.30

Energy Supply - Balancing Moderation and Innovation

Wednesday, September 26, 2007 | 9.30-12.30

Eat it or Burn it? The Potential of Bio Fuels

Thursday, September 27, 2007 | 9.30-12.30

White Biotechnology - Technology of the Future?

Friday, September 28, 2007 | 9.30-12.30

Sustainable Chemistry Thanks to Renewable Raw Materials 
Tuesday, September 25, 9.30-12.30

\section{Energy Supply - Balancing Moderation and Innovation}

Chairman Prof. Georg Fráter, President of the Swiss Chemical Society

\author{
Opening Dr. Walter Steinmann, Director of the Federal \\ Office of Energy \\ 'The Energy Challenge of Switzerland in the \\ Future' \\ Abstract 1
}

Speakers Dr. Fatih Birol, Chief Economist and Head of the Economics Analysis Division, International Energy Agency, Paris

'The IEA Annual Energy Outlook 2007'

Prof. Alexander Wokaun, General Energy Research Department, Paul Scherrer Institut 'Efficiency and Fossil Fuel Substitution The Contribution of Chemistry and Chemical Engineering'

Abstract 2

Prof. David Pimentel, College of Agricultural and Life Sciences, Cornell University, USA 'Ethanol Fuels versus Environmental, Food, and Pollution Costs'

Abstract 3

Panel discussion with the speakers and additional experts

Moderator Prof. Dieter Imboden, President of the Research Council of the Swiss National Science Foundation and Professor for Environmental Physics at ETH Zurich

\section{Abstract 1}

\section{The Energy Challenge of Switzerland in the Future}

Walter Steinmann

Swiss Federal Office of Energy, Bern

On behalf of the Swiss Federal Office of Energy, it is my pleasure and an honour to welcome you today to the Swiss Chemical Society's Scientific Forum at the ILMAC 2007 with its special focus on energy and raw materials as well as on the contributions of chemistry and biochemistry in the future.

Switzerland faces a number of significant challenges in the area of energy policy. Aspects such as securing the supply of energy, the limited reserves of fossil fuels, global climate change, the approaching end of the service life of Switzerland's existing nuclear power plants and the expiry of long-term electricity import agreements all mean that, sooner or later, changes in policy will have to be adopted. A number of pressing issues need to be addressed: How can we overcome the growing shortfall in domestic electricity supply? How can we achieve the declared climate protection objectives? Which targets will apply after 2012 and which objectives should SwissEnergy set itself in the long-term?
The mentioned challenges primarily concern the federal and cantonal authorities which, in accordance with the Federal Constitution, are obliged to take measures to ensure a sufficient, broad-based, secure, economical and environmentally compatible energy supply, and to promote the economical and efficient use of energy. Four years ago, in its report concerning its strategy of sustainable development, the Federal Council presented its vision of a '2000-watt society' as a long-term objective.

A number of political decisions will have to be taken in the near future since the federal government has to define its post-2012 policies relating to supply security and climate protection, including the required conditions for promoting energy efficiency and the increased utilization of renewable forms of energy. Other decisions need to be prepared but finalized at a later date. They include considering the deliberations on the part of the electricity sector concerning the construction of new nuclear power plants, and finding a suitable site for the safe storage of radioactive waste. Such decisions require a great deal of time, especially in a system of direct democracy, and they also have long-term impacts on the society, the environment and the economy.

In view of the situation outlined above, the Swiss Federal Office of Energy has established a '2035 energy perspectives workgroup' with the purpose of examining the scope for manoeuvre for future energy policy. To create a basis for discussion four energy scenarios have been developed and were presented in the final report on the 'energy perspectives for 2035'. Those scenarios show different possible developments of supply and demand for energy which have been calculated under 'if-then statements'. The energy perspectives indicate under which conditions, with the aid of which measures and through which practical means future energy policy can be structured and influenced.

The energy perspectives for 2035 make clear that - in consideration of the growing demand of energy - past measures are not sufficient to ensure a long-term supply security. In the case of fossil sources of energy such as oil and gas the supply security is insecure because of the dependence on foreign countries and on limited fossil resources. In addition to this, the emissions of $\mathrm{CO}_{2}$ need to be reduced in view of the global climate change. As to electricity - which meets approximately a quarter of the overall energy requirement - there will be a supply deficit due to the expiry of the import contracts and the limited life span of the nuclear power plants.

Therefore - based on the energy perspectives for 2035 - the Federal Council has specified a new energy strategy structured in four columns. These are energy efficiency, renewable energies, main power stations and foreign policy of energy.

By the end of this year plans of action will be presented concerning energy efficiency measures and the promotion of renewable energies. They will contain concrete suggestions on the stage of law and regulation as well as the strategy for a strengthened foreign policy. The political discussion will show how far the political consent goes when it comes to the realization of concrete demands. A simplification of the grant procedure is examined for main power stations and editions are specified, such as $\mathrm{CO}_{2}$-neutrality of gas power plants. Central subjects of the foreign policy are the negotiations with the European Union and the continuation of Post-Kyoto.

The energy strategy of the Federal Council has been developed in view of the immense challenges which we will have to face. On the global level the geopolitical conflicts around energy resources as well as the global climate change ask for intensified international cooperation. 
On the national level the energy future cannot be created only by a symbolic policy and the principle of voluntariness does not show the required results. Therefore we need longsighted private investments, individual change of behavior, and above all, we need legislations that are actually carried out. The solutions adopted in the future will be judged on the basis of the principles of sustainability, supply security, competitiveness and protection of the climate and the environment.

In this sense I consider the Swiss Chemical Society's Scientific Forum at the ILMAC 2007 an important platform for interdisciplinary discussions on future key issues and I am looking forward to finding technically and financially realizable solutions.

In conclusion I would like to thank you all for joining us in Basel and actively participating in this forum.

Walter Steinmann is the director of the Swiss Federal Office of Energy in Bern. He studied economics at the University of Zurich before completing his $\mathrm{PhD}$ thesis on 'The Interaction between State and Economy' at the University of Konstanz in 1988. He is the founding member of many organisations and initiatives such as the Innovationspreis beider Basel, Technologiestandort Schweiz, and the JUS Young Entrepreneurs School in Olten to encourage entrepreneurial activity in Switzerland. He was also a founding member of the 'Design Preis Schweiz' and 'BibUtz', a transfer organisation set up to deal with the mass redundancies arising from the closure of two paper factories. In 1998 he acted as the Secretary of the VDK conference for the ministers of the Cantonal Economy Departments

\section{Abstract 2 \\ Efficiency and Fossil Fuel Substitution - The Contribution of Chemistry and Chemical Engineering}

Alexander Wokaun

General Energy Research Department

Paul Scherrer Institut, Würenlingen

Demand side management, increased efficiency and substitution of fossil fuels are the three elements of climate protection strategy emphasized by the European Union, international bodies like the International Energy Agency, and many national governments. This presentation will concentrate on efficiency and substitution, as appropriate for the technological focus of research at the Paul Scherrer Institute. Examples will be chosen where chemistry and chemical engineering have made particularly important contributions.

Advanced construction and renovation concepts are key to reduce the heating energy demand of buildings. In this context, fiber-reinforced aerogel materials as fillers have enabled a major breakthrough in the application of vacuum insulation panels. Active ceilings containing phase-change materials and solar adsorption cooling systems are further examples of novel chemical engineering concepts applied in the building sector.

More efficient internal combustion engines, hybrid vehicles and fuel cell propulsion carry the main thrust in fuel consumption reduction for motorized individual transportation. The partial reforming of gasoline fuel on board of the vehicles carries the potential to strongly increase engine efficiency, while at the same time reducing pollutant emissions. - Increased lifetime and reduced cost are the main drivers for fuel cell development. Novel synthesis routes for high performance polymer electrolyte membranes, and preparation methods for active electrocatalysts with high platinum utilization are key for achieving the target specifications.

Industry has traditionally paid more attention to energy conservation as a major cost element. Chemical industry, in particular, has pioneered low-energy process variants, atomic and material efficiency, as well as waste stream valorization.

As for electricity production from natural gas, combustion chemistry has provided guidelines for the design of gas turbines with lowest $\mathrm{NO}_{x}$ emissions. Partial catalytic reforming of the fuel is attractive not only to further lower pollutant emissions, but also for novel process schemes that provide the option of $\mathrm{CO}_{2}$ separation for subsequent sequestration.

Turning to fossil fuel substitution, biomass-derived fuels are a major option for the transportation sector. Agricultural and forestry waste, whole plants and lignocellulosic biomass are the feedstock for second generation biofuels. As the rate and completeness of conversion are an issue in fermentation/enzyme-based processes, gasification schemes represent an important option. High-temperature gasification yields synthesis gas that can be further processed to Fischer-Tropsch type liquids or synthetic natural gas. Hydrothermal oxidation is emerging for the processing of biomass with high water contents.

Solar hydrogen production will be chosen as a final example. The intermittency problem of solar energy is addressed by direct chemical storage. As an example, the $\mathrm{ZnO} / \mathrm{Zn}$ thermochemical cycle consists of $\mathrm{ZnO}$ dissociation by solar energy radiation at temperatures above $2000 \mathrm{~K}$, a rapid quench of $\mathrm{Zn}(\mathrm{g})$ to induce nucleation and avoid reoxidation, and the closing of the cycle by $\mathrm{Zn}$ hydrolysis, producing hydrogen. We shall illustrate how solar reactor engineering addresses the challenges in each of the mentioned steps. The availability of hydrogen produced from renewable energies is a key requirement for introducing hydrogen as a $\mathrm{CO}_{2}-$ 'free' fuel for a much more efficient transportation.

Alexander Wokaun studied chemistry at the Swiss Federal Institute of Technology (ETH) in Zurich. In 1978, he received his $\mathrm{PhD}$ in the area of magnetic resonance with Richard R. Ernst. During a subsequent three-year stay at IBM and Bell Laboratories he focused on surface studies by laser spectroscopic techniques. From 1982 to 1985, he directed a program on surface energy transfer processes at ETH Zurich. In 1986, he became full professor of physical chemistry at the University of Bayreuth, with a research program comprising studies of materials surfaces, catalytic reaction mechanisms, and laser surface modification. Since 1994, he is the head of the General Energy Research Department of the Paul Scherrer Institut, and teaches in the Chemistry Department of the Swiss Federal Institute of Technology in Zurich. Development of a sustainable energy system is at the focus of the research program, which comprises technologies for the use of renewable energies, energy storage, clean and efficient energy converters, and assessment of the environmental consequences of energy use. Since 2006, Alexander Wokaun has been a member of the Advisory Group on Energy of the European Union. He chairs the Steering Committee of the Competence Center Energy and Mobility which facilitates large-scale collaborative projects of ETH domain institutions. 
Abstract 3

\section{Ethanol Fuels versus Environmental, Food, and} Pollution Costs

David Pimentel

College of Agricultural and Life Sciences

Cornell University, USA

Converting maize into ethanol uses more fossil energy than the energy contained in the resulting ethanol fuel. If all the energy inputs required to raise the maize and convert it into ethanol are counted, a negative energy return results. In total $43 \%$ more fossil energy is required to produce a liter of ethanol than the energy contained in the liter of ethanol.

The energy required to produce the maize alone involves 14 different inputs, including energy that is used in farm labor, farm machinery, fertilizers, pesticides, irrigation, plus other inputs. These are all typical crop inputs that agricultural economists include in their economic enterprise investigations for maize and other crops. Once harvested, several fossil energy inputs are required in the fermentation/distillation operation. Thus, the total energy required for maize production and the conversion into ethanol are enormous.

Some energy and economic credits are given for the by-products, such as the dried distillers grains (DDG). The 40-60\% energy credits given by some investigators are unrealistic because the DDG is not a fuel but cattle feed. Only small amounts of DDG can be fed to chickens and hogs.

Thus, ethanol production requires substantial fossil energy inputs; it contributes to the need for significant oil and natural gas imports from the Middle East and elsewhere.

The U.S. Department of Energy reports that 19 billion liters of ethanol were produced last year. This ethanol yield represents only $1 \%$ of total annual U.S. petroleum use and $20 \%$ of all U.S. maize production. If $100 \%$ of all U.S. maize were to be converted into ethanol, this would provide only $7 \%$ of our total petroleum use.

Currently, the U.S. subsidies for a liter of ethanol are 90 times greater than the subsidies for a liter of gasoline. Subsidies for ethanol and gasoline are major costs for the consumer.

The negative environmental impacts associated with ethanol production are many and significant. For example, growing maize causes severe soil erosion and requires more nitrogen fertilizer than any other crop grown. Also, maize production requires more insecticides and herbicides than any other crop. These chemicals are major environmental pollutants. Large quantities of water (about 1,700 liters) are required to produce one liter of ethanol.

Enormous quantities of carbon dioxide are produced in the production of ethanol. The large quantity of fossil energy used in production, large quantities of carbon dioxide released during fermentation, and the tilling of soil that results in organic matter being exposed and oxidized, are all processes that release carbon dioxide and speed global warming.

A further consideration is the impact of the conversion of millions of tons of a major crop used to feed humans and livestock. This increases the cost of meat, milk, and eggs and also diminishes the U.S. export of grain crops to poor populations. The expenditures to U.S. consumers for meat, milk, and eggs are now increasing to about $\$ 20$ billion per year because of ethanol production.

Biodiesel using soybeans, canola, or sunflower has as many negative energy returns as maize production. Although there are fewer fossil energy inputs for the produc- tion of these biodiesel crops, their crop and fuel yields are about one third smaller than those for maize.

Basically, ethanol and biodiesel production in the United States will not provide a positive energy return and cannot produce the net energy needed by the U.S. Biofuel production does not benefit the nation's future energy security. The production of maize for ethanol has major costs in terms of eroded U.S. agricultural land, consumption of freshwater, and the use of imported fossil energy. Overall, ethanol production reduces environmental quality.

Instead, the focus should be on establishing a major energy conservation effort, improving fuel efficiency in cars, and expanding renewable energy technologies, such as wind power and photovoltaic cells.

David Pimentel is a professor of ecology and agricultural sciences at Cornell University, Ithaca, NY 14853-0901. $\mathrm{His} \mathrm{PhD}$ is from Cornell University. His research spans the fields of energy, ecological and economic aspects of pest control, biological control, biotechnology, sustainable agriculture, land and water conservation, and environmental policy. Pimentel has published more than 600 scientific papers and 23 books and has served on many national and government committees including the National Academy of Sciences; President's Science Advisory Council; U.S Department of Agriculture; U.S. Department of Energy; U.S. Department of Health, Education and Welfare; Office of Technology Assessment of the U.S. Congress; and the U.S. State Department.

Wednesday, September 26, 9.30-12.30

\section{Eat it or Burn it? The Potential of Bio Fuels}

Chairperson Charlotte Opal, Coordinator of the 'Roundtable on Sustainable Biofuels', Energy Center, EPFL

Speakers Tim Kroenke, Global Head of Biofuels, Syngenta International AG, Basel

'The Promise and Challenges of Current Crop-to-Fuel Regimes and Cellulosic Ethanol' Abstract 4

Dr. Gunter Festel, Festel Capital, Hünenberg, Zug

'Biofuels - Which One is the Most Economic One?'

Abstract 5

Dr. Rainer Zah, Technology and Society Laboratory, EMPA

'Biofuels - Which One is the Most Ecological One?'

Abstract 6

Panel discussion with the speakers and additional experts

Moderator Helen Issler, Schweizer Fernsehen 
Abstract 4

\section{The Promise and Challenges of Current Crop-to-Fuel Regimes and Cellulosic Ethanol}

Tim Kroenke

Global Head of Biofuels, Syngenta International AG, Basel

Over the past six years the volume of biofuels produced and consumed globally has been growing at a rate of more than $15 \%$ per annum, yet currently account for less than $2 \%$ of global transportation fuels, In this presentation Mr. Kroenke will explore the potential and challenges for current crop-to-fuel regimes around the world as well as that of cellulosic ethanol. He will also illustrate the growing role Syngenta $A G$ is playing in this dynamic industry.

Tim Kroenke oversees global biofuels business development at Syngenta AG. In this role he is responsible for identifying, investigating, developing and launching new business opportunities in the biofuels field for Syngenta. During his career Mr. Kroenke has overseen agricultural businesses in the United States and globally for Syngenta. $\mathrm{He}$ has also held various positions in business development, product management and marketing. He received his B.S. in Agricultural Economics and his M.S. in Agricultural Marketing from the University of Wisconsin, Madison, U.S.A.

\section{Abstract 5}

\section{Biofuels - Which One is the Most Economic One?}

Gunter Festel

Festel Capital, Hünenberg, Zug

Due to the many different influencing factors of biofuels, such as technical (e.g. raw material supply, conversion and engine technologies), economical (e.g. fuel and engine modification costs, infrastructure) and ecological/political factors (e.g. greenhouse gas emissions, efficient land use, reduced dependency on crude oil), there is a tendency to get lost in details when trying to identify interesting technological opportunities.

In order to carry out a quantitative comparison of the different biofuels to identify interesting technologies the complex coherences were reduced to the most important influencing factors. An analysis of customer acceptance and attitude towards biofuels showed that important to customers are prices no higher than those of fossil fuel, no engine modification costs or loss of power, high availability and easy handling. Therefore, biofuels need to meet the following criteria: competitive production costs, no additional distribution/infrastructure costs, problem-free blending with existing fuel types as well as similar chemical/physical properties. Therefore, as costs for the customer are a deciding factor for market success over the short to mid term, our comparative analysis considered only the economical factors and not the ecological aspects.

In order to identify interesting biofuel technologies for investors publicly obtainable data with regard to production costs were evaluated and included in a consistent model calculation. Besides plausibility checks, data comparability was evaluated and, if necessary, corrections were made. The results showed the costs and profit margins of the considered biofuels. As well as the raw material costs and production costs also the capital costs, blending costs and distribution costs to the filling pumps were calculated for each fuel separately. In order to reflect the various development stages and the economies of scale, realistic scenarios were calculated. In the calculation and comparison the normal mineral oil tax was considered also for biofuels. The profit margin (price at the filling station minus all costs and taxes) was the criterion for the profitability.

In the evaluation, a price of US\$ 60 per barrel of oil for petrol and diesel production was taken and the results were conclusive. Both biodiesel and bioethanol produced in Europe from wheat are not profitable. The producers' high margins are only due to the current mineral oil tax concessions. At present, biomass-to-liquids (BTL) fuel can also not be produced competitively. At the taken oil price, only bioethanol and biobutanol produced on a large scale from lignocellulose-containing raw materials have the potential to be produced competitively.

It can be concluded that in Europe biobutanol produced from straw is mid term the most cost-effective biofuel, which can be produced with a reasonable profit margin also without tax exemption. The analysis of the technologies in this field shows that there are interesting new technological developments in Europe for the hydrolysis, fermentation and purification step. Our model calculation, which is the basis for the development of an integrated butanol production process, shows that it is possible to produce biobutanol with 35 Euro cent/litre ( 0.10 raw material, 0.15 conversion, 0.10 capital).

Gunter Festel founded at the beginning of 2003 the advisory and investment firm FESTEL CAPITAL with headquarters in the Swiss Cantone Zug. His company specializes in the commercialization of technologies in the areas of energy, environment, health, materials as well as nutrition and invests in selected companies, preferably in early stages. One focus topic is supporting buy-outs, spin-offs and start-ups from business planning through transactions up to business optimization.

Up to the end of 2002, Gunter Festel was a member of the management team and head of the consulting business for the chemical and healthcare industry with Arthur D. Little in Zurich and a consultant with McKinsey. He started his career with Bayer, where he held various management positions in R\&D and marketing. Gunter Festel received his $\mathrm{PhD}$ in chemistry, BA in business studies and MA in economics. Furthermore, he has an Executive Master of Corporate Finance.

\section{Abstract 6 \\ Biofuels - Which One is the Most Ecological One?}

Rainer Zah

Technology and Society Laboratory, EMPA

In connection with the increasing scarcity of fossil fuels and climate change the idea of using renewable energy is attracting interest both in the Swiss public eye and in industry. Fuels made from biomass - so-called biofuels - are currently the most important form of renewable energy in road transportation and could at least over the short to medium term take on a role in reducing greenhouse gases and our dependency on fossil fuels.

Although biofuels from renewable resources exist, a wider range of environmental impacts may result from their cul- 
tivation and processing than those from fossil fuels. These range from excessive fertilizer use and acidification of soil to a loss of biodiversity caused by slash and burning rainforest. Besides that, one should not forget that expanding agricultural energy production may lead to land-use conflicts with other land uses such as food production or the conservation of natural areas. Therefore energy efficiency and the attainable reduction in greenhouse gases should not be taken as the sole criteria for a holistic environmental evaluation of these alternative fuels.

The objective of this presentation is to demonstrate the environmental impact of the entire production chain of various fuels made from biomass, in particular biodiesel, bioethanol, and biogas. The results are based on the Swiss database of environmental inventories ecoinvent and give a holistic comparison of the environmental impacts of biofuels; however neither the costs of biofuels nor the social consequences of their production are evaluated. The results refer to average values from the year 2004 in the respective production countries and are to be taken as a snapshot of factors relevant to the fuels' use in Switzerland. Thus the study cannot provide any answers to questions concerning future impacts - for instance, on food prices.

In principle, each of the fuels examined can be produced in an environmentally friendly way - it depends on what raw materials and production technologies are used. Most of the environmental impacts can be attributed to the agricultural cultivation of the respective raw materials (feedstocks). The environmental impact from fuel processing is usually much lower. The environmental impact from the transport from the production site to Swiss filling stations is even less, even when the biofuels are produced overseas. The present study shows that with most biofuels there is a trade-off between minimizing greenhouse gases (GHG emissions) and a positive environmental life cycle assessment (LCA). It is true that GHG emissions can be reduced by more than $30 \%$ with a number of biofuels. However most of these supply paths show greater impacts than petrol for various other environmental indicators.

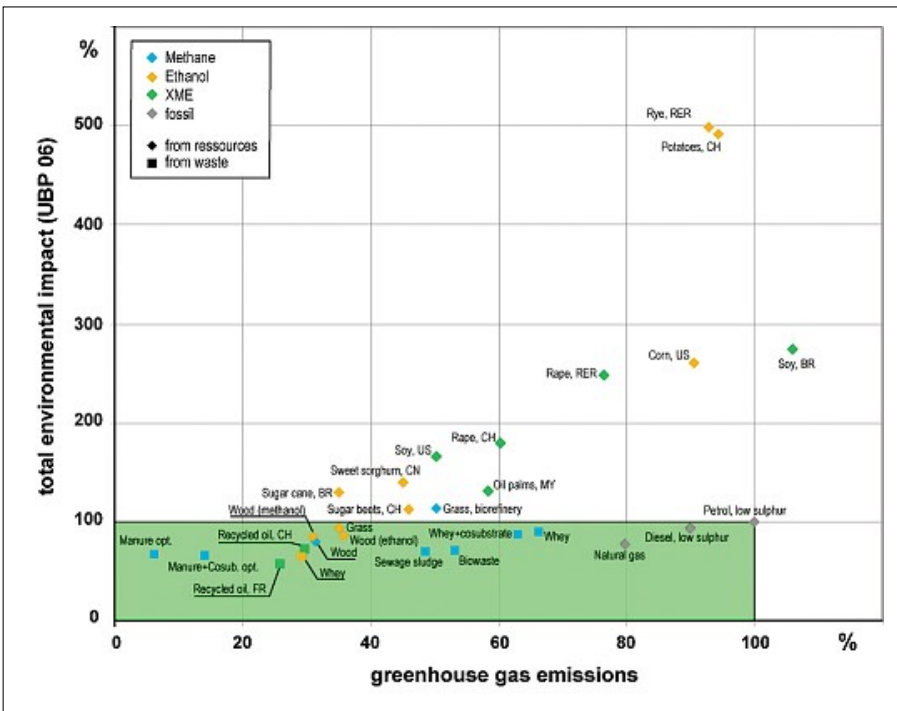

Two-dimensional representation of GHG emissions and overall environmental impact (UBP 06). Values are relative to fossil reference petrol. The green area means both lower GHG emissions and lower overall environmental impact than petrol.

The environmental LCA was done using two different methods: one was the Swiss method of ecological scarcity (Environmental Impact Points, UBP 06, reg. Fig.), which evaluates the difference between environmental impacts and legal limits. The other one is the European Ecoindicator 99 method, which quantifies the damage done to human health and ecosystems. Both methods show the same results: in the case of tropical agriculture it is primarily the slashing and burning of rainforests that releases the largest quantities of $\mathrm{CO}_{2}$, causes an increase in air pollution and has massive impacts on biodiversity.

In the moderate latitudes it is partly the lower crop yields, partly the intensive fertilizer use and mechanical tilling of the soil that are the causes of a bad environmental evaluation. However unlike the case of fossil fuels, the environmental impacts of biofuels can be greatly reduced by specific measures. The study shows in a sensitivity analysis how, for instance, a reduction in methane leakage can improve the LCA of biogas production or what effect a prohibition of slash and burn would have on the LCA of biodiesel made from palm oil.

Overall, the results of the study show that any promotion of biofuels by a tax break, for instance, must be done so as to target the best production paths. Not all biofuels per se can reduce environmental impacts as compared to fossil fuels. Currently, of all the production paths investigated, it is especially the use of biogenic wastes ranging from grass to wood that brings a reduction in environmental impact as compared with petrol. Since the potential of domestic bioenergy today is limited - and will be so in future - bioenergy will not solve our energy problems. However if the available biomass is transformed into energy in an efficient and environmentally friendly manner, while at the same time consumption is reduced and energy efficiency increased, these alternative energy carriers can together with other forms of renewable energy play a role in our future energy supply that should not be neglected.

Dr. Rainer Zah, born in Winterthur in 1968, is deputy head of the Technology \& Society Lab and head of the group Information Systems \& Modelling at the Swiss Federal Laboratories for Materials Testing and Research (EMPA). As an environmental scientist and specialist for geographic information analysis and remote sensing, his main research interest is the spatial dimension of environmental problems induced by technology. Current projects include the spatial modeling of environmental emissions in Latin American cities based on environmental inventories, and the integrated assessment of bioenergy options for Switzerland. 


\section{Thursday, September 27, 9.30-12.30}

\section{White Biotechnology - Technology of the Future?}

Chairman Dr. Beat Wipf, Head of Section Protein Science, F. Hoffmann-La Roche

Speakers Prof. Wim Soetaert, Laboratory for Industrial Microbiology and Biocatalysis, Ghent University, Belgium

'White Biotechnology: A Key Technology for Building the Biobased Economy' Abstract 7

Prof. Bärbel Hahn-Hägerdal, Lund Institute of Technology, Sweden

'Biotechnology Applied in the Traditional Process Industry'

Abstract 8

Dr. Marco Oldiges and Prof. Christian

Wandrey, Institute of Biotechnology, Research Center, Jülich, Germany

'White Biotechnology: Why Do We Need It Today?'

Abstract 9

Panel discussion with the speakers and additional experts

Moderator Dr. Christian Heuss, Schweizer Radio DRS

\section{Abstract 7 \\ White Biotechnology: A Key Technology for Building the Biobased Economy}

Wim Soetaert

Laboratory for Industrial Microbiology and Biocatalysis, Ghent University, Belgium

At present, a third wave of biotechnology - industrial biotechnology - is developing strongly. Industrial biotechnology (also referred to as white biotechnology) stands apart from red biotechnology (directed towards health care) and green biotechnology (genetic modification of agricultural crops). Industrial biotechnology is the application of biotechnology for the industrial production and processing of chemical substances, materials and bio-energy. Industrial microbiology mainly uses micro-organisms and their enzymes to make useful products, materials and processes in the areas of chemistry, food and feed, paper and pulp, textiles, energy supply, etc. Micro-organisms (bacteria, yeasts, fungi and micro-algae) are 'cell factories', capable of performing highly efficient chemistry for the industrial production and processing of bulk chemicals, fine chemicals, food ingredients, pharmaceutical ingredients, bio-fuels, bio-plastics, etc.

Industrial biotechnology is a multidisciplinary technology that is an effective integration of different fields such as biochemistry, microbiology, fermentation science, biocatalysis, metabolic engineering, microbial genomics and proteomics, bio-informatics, chemical process engineering and down-stream processing. It is an enabling technology that finds application in a wide range of industries.

Industrial biotechnology typically relies on the use of renewable resources as raw materials instead of fossil re- sources such as petroleum. As such, it can reduce our dependency on increasingly expensive petroleum, contribute to attaining the Kyoto objectives by reducing greenhouse gas emissions, and provide significant support for European agriculture by creating new markets for agricultural commodities.

New and innovative products can be produced through industrial biotechnology and through integration of biotechnology in industrial production processes (bio-manufacturing), these can generally be made more economical, environmentally friendly and sustainable. The way industrial biotechnology can combine both economical and ecological progress is quite typical.

The combination of all these factors is currently driving the strong penetration of industrial biotechnology in all sectors of the chemical industry, particularly in fine chemicals but equally so for bulk chemicals such as plastics and fuels. Also other industrial sectors such as the food and feed industry, textile industry, consumer industry, paper and pulp industry, the energy sector and others rely increasingly on the incorporation of biotechnology in their processes.

Wim Soetaert is professor for industrial biotechnology at Ghent University, Belgium. He has a degree in chemical and biochemical engineering (Ghent University, 1987) and holds a PhD in bioengineering (Ghent University, 1991). He worked from 1991 until 1998 for the German sugar group Pfeifer \& Langen as the group research director. From 1998 until 2002 he was the Director for Research \& Development of Chamtor, a French glucose and starch processing company.

In 2003 Wim Soetaert became full-time professor at Ghent University (Belgium), working in the Laboratory for Industrial Microbiology and Biocatalysis of the Faculty of Bioscience Engineering. His research group is active in the areas of industrial biotechnology, biocatalysis and fermentation science and engineering.

$\mathrm{He}$ is the vice-chairman of ESAB, the Section Applied Biocatalysis of the European Federation of Biotechnology. Wim Soetaert has been awarded the European Cereal Prize (first prize) twice, in 1993 and again in 1998.

Abstract 8

Biotechnology Applied in the Traditional Process Industry

Bärbel Hahn-Hägerdal

Lund Institute of Technology, Sweden

The prospects of global warming and the potential future shortage of fossil chemical feed-stocks have turned the interest towards utilization of renewable raw materials derived from agriculture and forest products. Such raw materials - lignocellulosics - are composed of lignin, cellulose and hemicellulose. In a bio-refinery concept the raw material may be pre-treated at elevated temperatures with small amounts of dilute acid or $\mathrm{SO}_{2}$ to make cellulose and hemicellulose accessible to subsequent acid or enzymatic hydrolysis. During pre-treatment and acid hydrolysis fermentation inhibitors - phenol and furan derivatives and low molecular weight fatty acids - are released. Cellulose and hemicellulose are hydrolyzed to fermentable monomer sugars (glucose, mannose, galactose, xylose and arabinose), while lignin is recovered as a solid fuel. 
Hydrolyzed lignocellulosic raw materials thus comprise a mixed-sugar substrate in an inhibiting matrix. Because of its high inhibitor tolerance, its wide biological activity and its proven record as industrial fermentation micro-organism, Baker's yeast Saccharomyces cerevisiae is the prime choice of micro-organism for a bio-refinery. The presentation will address how the advent of modern DNA-technology including metabolic engineering and evolutionary engineering as well as the concept of systems biology permits the development of recombinant $S$. cerevisiae with novel and artificial activities to be exploited in the energy, chemicals and materials industries.

Bärbel Hahn-Hägerdal is professor of Applied Microbiology at LTH/Lund University, Sweden. Her research concerns the development of industrial strains of yeast for the fermentation of lignocellulosic hydrolysates with special emphasis on recombinant pentose fermenting strains of Saccharomyces cerevisiae. She gained a PhD in biochemistry from Lund University followed by a post-doctoral fellowship at the University of Pennsylvania, USA. She has been a visiting scientist at AIST, Tsukuba, Japan, and a visiting professor at universities in South Africa and Brazil. She is an Honorary Professor at the University of the Free State, Bloomfontein, SA. She serves as Swedish representative on the IEA task 'Bioconversion of Lignocellulosics' and on the International Commission for Yeast. She has coordinated a number of national, Nordic and EU research projects with focus on metabolic engineering. Her research has resulted in more than 250 publications, and a number of patents and patent applications. Under her supervision more than $30 \mathrm{PhD}$ students have graduated. She is regularly engaged in reviewing research papers for international scientific journals and research proposals for the EU and for scientific societies in Europe and overseas. She serves on the board of the Swedish Research Council and as president of the Royal Physiographic Society in Lund.

\section{Abstract 9}

\section{White Biotechnology: Why Do We Need It Today?}

Marco Oldiges* and Christian Wandrey

Institute of Biotechnology, Research Center, Jülich, Germany

Nowadays, the definition of White Biotechnology is well established and generally accepted in the meaning that it "is the application of nature's toolset to industrial production".[1]

In 1902, already one century earlier and long before people knew about molecular biology or J. D. Watson and F. Crick were even born, Emil Fischer, a genius in the field of chemistry, had already "foresee(n) the day when physiological chemistry will not only make extensive use of the natural enzymes as agents, but when it will also prepare synthetic enzymes for its purposes". [2] These so-called synthetic enzymes are now state of the art technology in every molecular biology or biotechnological laboratory all over the world. This not only demonstrates that Emil Fischer was right, but also indicates that these technologies of manipulating nature's toolset are already being applied for useful products.
In the past these products were often fine chemicals or chiral compounds of high value and small world market volume, but with reasonable margins. Now, we are heading towards a White Biotechnology future where intermediates and bulk chemicals are produced by biotechnological processes (e.g. 1,3-propanediol, ethanol, polylactic acid, acrylamide, L-lysine, L-glutamic acid, citric acid). It turns out that biotechnological processes have advantages in terms of economics and are even superior in terms of ecologics and sustainability, since they are based on renewables.

In contrast to the crude oil processing supply chain (i.e. refining, cracking) which successively adds chemical functionalities during conversion to bulk chemicals (e.g. ethylene $\rightarrow$ ethanol), renewable resources have to be defunctionalized (e.g. glucose/saccharose $\rightarrow$ ethanol) to serve as feedstock for chemical industry. Since nature provides a lot of chirality for free, the more efficient use of the chiral pool could be improved in industrial application.

For ethanol, as an example for a potential chemical feedstock and biofuel, the production costs in Brazil show that ethanol is already competitive as chemical feedstock and even on an energetic level as biofuel. Typical for bulk chemicals the ethanol production costs are dominated by the raw material. Brazil can rely on 550 million ha arable land which is more than the total area of approximately 32 European countries. Compared to Brazil, Germany $(2.2 \%)$ and Switzerland $(0.2 \%)$ only have a minor amount of suitable land area and are not compatible for the generation of raw materials. In addition the geographical circumstances in Brazil favour a doubled biomass formation per area while operational costs are less than 50\% compared to Europe.

In order to compensate for this, Europe must rely on technology, e.g. integrated biochemical engineering, omics technologies, technical evolution of bioprocesses, rational evolution of enzymes, whole cell engineering and a quantitative understanding of complex metabolic and regulatory networks. This technology will push forward biotechnological processes, invent new techniques, processes and products and bring them to market as the necessary consequence of a bio-based paradigm shift in the chemical industry. Moreover, Europe has a long tradition in setting benchmarks in chemical engineering and can make substantial contributions to the processing and refining of biorenewables. Nowadays, Europe's industry depends on crude oil and natural gas imports, but there is no reason why this could not change to the import of sugar or renewable biomass sources in the near future.

To feed the chemical industry supply chain several compounds are in the focus to become important platform chemicals. Among them are e.g. ethanol, acetic acid, glycerol, lactic acid, 5-hydroxymethylfurfural. A detailed list of more than 130 current White Biotechnology products has been collected by DECHEMA in their position statement 'Weiße Biotechnology - Chancen für Deutschland'.[3] Also politics has recognized the potential of White Biotechnology and the American government, as well as the European Union and national funding activities support White Biotechnology research and especially its further application in industry. The German ministry of research and education (BMBF) will support White Biotechnology clusters with 150 Mio. $€$ in the next five years and the European Commission has incorporated industrial biotechnology as an important element of the $7^{\text {th }}$ framework.

In the future great changes in bioprocess development will occur, since this field will become more and more important economically and competitively in a globalized White 
Biotechnology. Although still a key factor for success, the genetic improvement of biocatalysts must be accompanied with more efficient bioprocess development, since this can make the economic difference for low value and bulk products. Hence, an integrated and quantitative approach to predict complex metabolic network behavior is becoming a key success factor. Moreover downstream processing is gaining in importance. Also in this field a better quantitative understanding of the separation processes as function of molecule parameters is in reach. Since classical raw materials (crude oil, natural gas) are becoming more and more expensive, the chemical industry is willing to shift to renewable resources, i.e. a biobased chemical industry.

What is left to say? We have to go back in our labs and pilot plants, both in academia and industry. And we have to be quick, since evolution has already shown us that in a fast changing environment not the most efficient, but the quickest will win.

[1] EuropaBio: The European Association for Bioindustries, http://www.europabio.org/

[2] Emil Fischer, 'Syntheses in the purine and sugar group', Nobel Lecture, December 12, 1902.

[3] DECHEMA e.V., position statement, 'Weiße Biotechnology - Chancen für Deutschland', http://wbt.dechema.de/ Positionspapier.html

Marco Oldiges is the head of the Fermentation Technology Group at the Research Center Jülich, Germany. He completed his degree in chemistry and technical chemistry at the University of Bonn in 2000 before gaining his PhD in 2004 at the Institute of Biotechnology at the Research Center Jülich. His research interests include development of experimental and analytical techniques for metabolome and metabolic flux analysis and their application for rational bioprocess development and metabolic engineering. He is a member of the 'Zukunftsforum Biotechnology' (DECHEMA e.V.) and his research activities are part of third-party funding with industrial and governmental partners.

\section{Friday, September 28, 9.30-12.30}

\section{Sustainable Chemistry Thanks to Renewable Raw Materials}

Chairman Prof. Hans Björn Püttgen, Director of the Energy Center, EPFL

Speakers Prof. Jürgen O. Metzger, Department of Pure and Applied Chemistry, University of Oldenburg, Germany 'Concepts on the Contribution of Chemistry to a Sustainable Development: Renewable Raw Materials' Abstract 10

Dr. Hans-Peter Meyer, Assistant Vice-President of Lonza, and Cathy Kroll, Swiss Biotech Association

'White Biotechnology in Switzerland Perspectives for a Sustainable Development' Abstract 11

Prof. Johann P. M. Sanders, Agrotechnology and Food Sciences Group, Wageningen University, Netherlands

'Biorefinery - The Bridge between Agriculture and Chemistry'

Abstract 12

Prof. Hans Björn Püttgen, Director Energy Center, EPFL

The 'Roundtable on Sustainable Biofuels':

A Multi-Stakeholder Process

Abstract 13

Abstract 10

Concepts on the Contribution of Chemistry to a Sustainable Development: Renewable Raw Materials

Jürgen O. Metzger

Department of Pure and Applied Chemistry, University of Oldenburg, Germany

The principles of the United Nations Conference on Environment and Development (UNCED), held in June 1992 in Rio de Janeiro, the World Summit on Sustainable Development, held in August 2002 in Johannesburg, and Agenda 21 , the comprehensive plan of action for the $21^{\text {th }}$ century, adopted 15 years ago by more than 170 governments, address the pressing problems of today and also aim at preparing the world for the challenges of this century. ${ }^{[1,2]}$ We should keep in mind that these documents should be our compass to assess sustainability. ${ }^{[3]}$

Here we want to discuss some of the many unsolved problems on the way to sustainable development as outlined in Agenda 21 and some aspects of renewable feedstocks for the chemical industry exemplarily referring to Chapter 4 'Changing Consumption Patterns' focusing "on unsustainable patterns of production and consumption" and "national policies and strategies to encourage changes in unsustainable consumption patterns". The conservation and management of resources for development are the main focus of interest, to which the sciences will have to make considerable contributions. 
"Reducing the amount of energy and materials used per unit in the production of goods and services" is an important aim of Agenda 21. However, a reduction factor of four ${ }^{[4]}$ or even ten ${ }^{[5]}$ is thought to be necessary on the way to a sustainable development. In addition to the demand for food, the demand for other goods will grow substantially with an increasing adaptation of the standard of living in the developing countries to the industrialized countries. It is a real challenge for chemists and chemical engineers to realize this goal in chemical processes and products. Chemistry may contribute to the conservation of resources by the development of

- more efficient and environmentally more benign chemical processes to reduce the energy consumed in chemical industry,

- chemical products that are environmentally more benign and enhance significantly the efficiency of production processes and products in other manufacturing areas to reduce the energy consumed in all manufacturing processes, and finally and most important

- by development of products that allow the consumer to use resources more efficiently to reduce the amount of energy and materials consumed in daily life. [6]

Base chemicals, chemicals that are produced worldwide in more than one million tonnes per year each are particularly significant with respect to the conservation of resources. A large part of the energy in the chemical industry is used for base chemicals and most energy may be saved by potentially improving their production processes. The gross energy requirements - the requirements of fossil energy used for the production of some important base chemicals are given in Fig. 1. It is evident that all petrochemical base chemicals have a much higher gross energy requirement - the sum of process energy and fossil feedstock energy - than base chemicals derived from biomass such as ethanol and rape seed oil having zero feedstock energy.

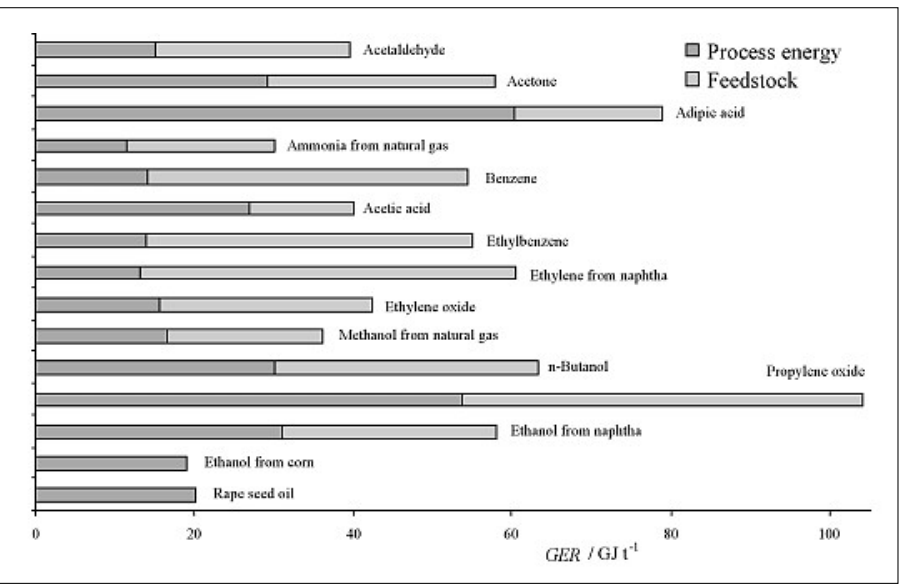

Fig. 1. Gross energy requirements (GER) for important base chemicals. Data are taken from ref. [6c].

Here, the differences in fossil resource consumption are so high that it can be assumed that products based on renewables must clearly be more sustainable than petrochemical products. Most interesting is the fact that the gross energy requirement (GER) of ethanol derived from corn is only one third of that of petrochemical ethanol. Thus, clearly, we should begin to substitute petrochemical base chemicals by renewables. Propylene oxide, the base chemical with the highest GER, will be considered in more detail and exemplarily.

Propylene oxide is one of the top 50 chemicals. More than 4 million t/a are produced worldwide. It is reacted via polyetherpolyoles with diisocyanates derived from diamino compounds to form polyurethanes and via propylene glycol with diacids polyesters to form polyesters. The polyol and diol functionalities required for these transformations are available from renewable feedstocks: carbohydrates, oils and fats, proteins and lignins. Without any doubt, it should be possible to develop alternatives to propylene oxide and other oxidized base chemicals based on renewable feedstocks.

The biomass cycle (Fig. 2) shows the advantages of renewable feedstocks. Biomass is formed by photosynthesis; extraction gives the renewable feedstocks such as vegetable oil, starch and others. These are processed to give the renewable base chemicals such as fatty acids, glycerol, glucose etc. Further processing gives useful products that after utilization can be biologically degraded to give again carbon dioxide and water. That is the ideal type of biomass cycle giving no additional carbon dioxide. Of course, some process energy is used by the farmer, the fertilizer, the extraction and processing. However, the chemical energy accumulated in the product comes entirely from the sun. In contrast, petrochemicals are derived completely from fossil feedstock. Most importantly, when renewables are used as base chemicals for organic synthesis, nature's synthetic input has to be used to obtain in one or only very few chemical reaction steps those complex molecules which petrochemically are only accessible in multistep reaction sequences, thus reducing the process energy as well. Thus, the encouragement of the environmentally sound and the sustainable use of renewable natural resources is an important aim of Agenda 21.

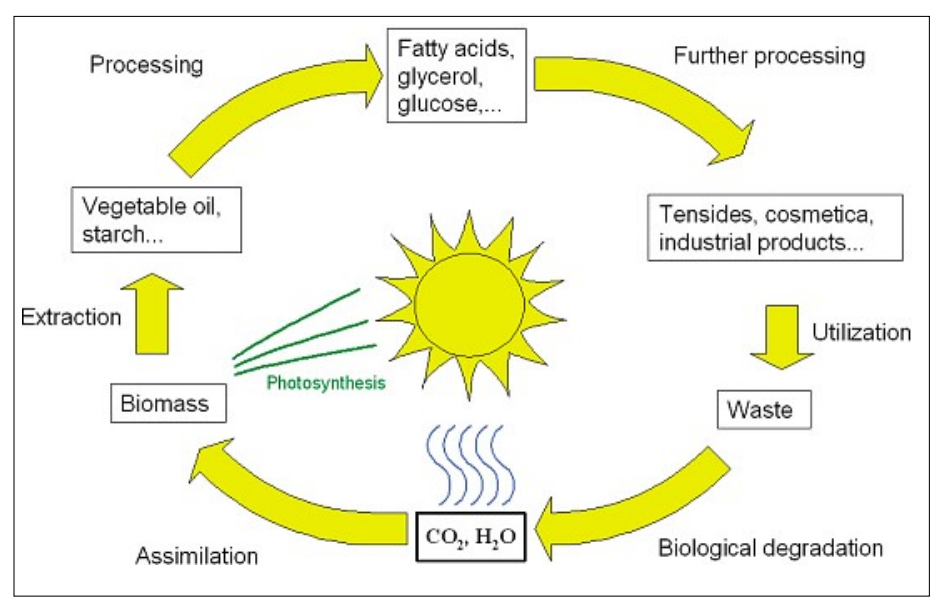

Fig. 2. Biomass cycle

The production and consumption of biodiesel in Germany in 2005 was more than 1.6 million tonnes and in the European Union more than 3.1 million tonnes. The production capacity increased in 2006 in Germany to more than 2.6 million tonnes and in the European Union to more than 6.0 million tonnes and will increase further. Biodiesel can be used as chemical feedstock as well. However, more important in this context is the fact that with the production of each tonne of biodiesel about 0.1 tonne of glycerol is produced i.e. more than 300,000 tonnes in 2005 , and in 2006 about 600,000 tonnes in the EU. The traditional glycerol market in the EU was about 220,000 tonnes per year. Thus, outlets for this new emerging source of glycerol have to be developed. It is intriguing to follow the on-going substitution of production processes of base chemicals such as 1,2-propanediol (1.6 million tonnes/year), and epichlorohydrin (1.2 million tonnes/year) based on petrochemical feedstock by 
new processes based on glycerol (Scheme). In the long run, renewable resources will replace fossil raw materials.

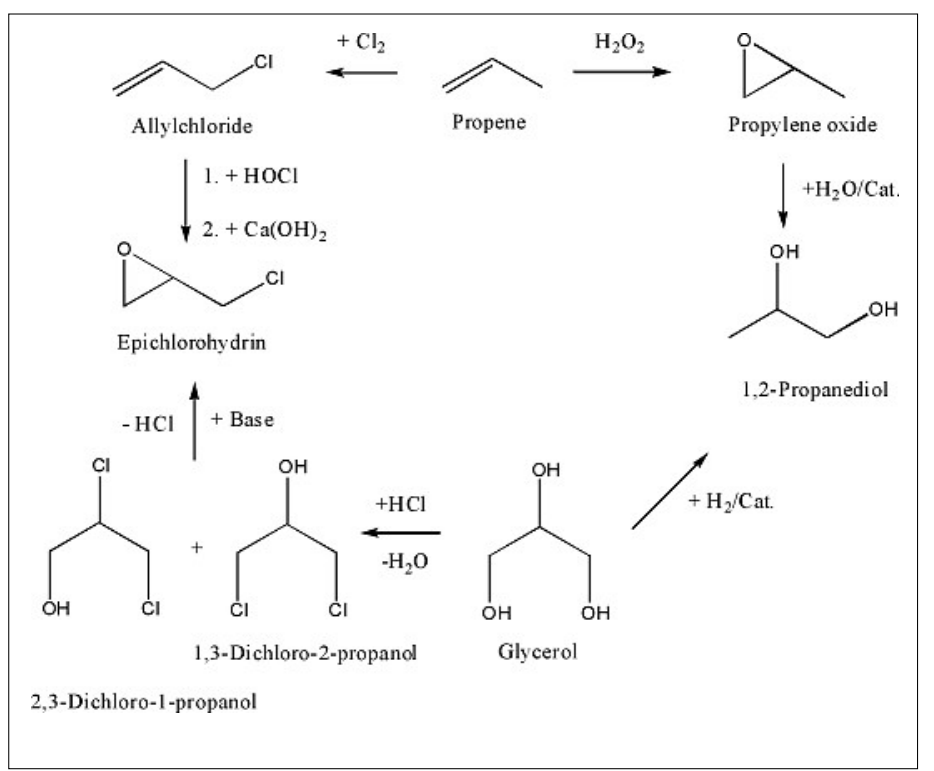

Scheme. Synthesis of 1,2-propanediol and of epichlorohydrin based on petrochemical (top) and renewable (bottom) feedstock, respectively

However, it will be difficult to substitute the entire fossil feedstock because an important problem that is closely connected with the industrial use of renewables for the production of chemicals, fuels as well as energy is the competition of the cultivation of food on the limited available agricultural area. ${ }^{[7]}$ Food demand and consumption will increase dramatically. The world population will rise from presently more than 6 billion to about 9 billion in 2050.[8] Existing forests may be used only partially for feedstock supply because of economical, various ecological and social reasons. It has been suggested that the competition of the cultivation of food and of feedstock for industrial use may be met by a global program of reforestation of areas laid waste in historical times by human activities and to use the biomass grown on these areas continuously for the production of the necessary energy, fuel, materials and chemicals. ${ }^{[9]}$

[1] Report of the United Nations Conference on Environment and Development, Rio de Janeiro, 3-14 June 1992, http:// www.un.org/esa/sustdev

[2] Johannesburg Declaration on Sustainable Development and Johannesburg, Plan of Implementation; http://www.un.org/ esa/sustdev

[3] J. O. Metzger, Green Chem. 2004, 6, G15-16.

[4] E. U. von Weizsäcker, A. B. Lovins, L. Hunter, 'Factor Four: Doubling Wealth - Halving Resource Use. A New Report to the Club of Rome', St Leonards, Australia, 1997.

[5] F. Schmidt-Bleek, 'Das MIPS-Konzept, Weniger Naturverbrauch - mehr Lebensqualität durch Faktor 10', Droemer \& Knaur, Munich, 1998.

[6] a) M. Eissen, J. O. Metzger, E. Schmidt, U. Schneidewind, Angew. Chem., Int. Ed. 2002, 41, 414-436; b) J. O. Metzger, M Eissen, C. R. Chimie 2004, 7, 569-581; c) J. O. Metzger, U. Biermann, 'Sustainable Development and Renewable Feedstocks for Chemical Industry', in 'Feedstocks for the Future: Renewables for the Production of Chemicals and Materials', Eds. J. J. Bozell, M. K. Patel, ACS Symposium Series 921, American Chemical Society, Washington D.C., 2006, 13.

[7] M. Wackernagel, N. B. Schulz, D. Deumling, A. C. Linares,
M. Jenkins, V. Kapos, C. Monfreda, J. Loh, N. Myers, R. Norgaard, J. Randers, Proc. Natl. Acad. Sci. USA 2002, 99 , 9266-9271.

[8] J. Bongaarts, R. A. Bulatao, 'Beyond Six Billion: Forecasting the World's Population', Panel on Population Projections, Committee on Population, National Research Council, Washington, D.C., 2000, http://www.nationalacademies.org.

[9] A. Hüttermann, J. O. Metzger, Nachr. Chem. 2004, 52, 11331138.

Jürgen O. Metzger, born in 1940, studied chemistry in Tubingen, Erlangen, Berlin, and Hamburg. He gained his doctorate at the University of Hamburg in 1970 on Ziegler Natta catalysts with $\mathrm{H}$. Sinn and his habilitation at the University of Oldenburg in 1983 on the topic: 'Thermally initiated intermolecular organic reaction at elevated temperatures and pressures, and reactions under supercritical conditions'. In 1991, he was appointed Professor of Organic Chemistry at the University of Oldenburg. His research interests include sustainability in chemistry, environmentally benign organic synthesis, renewable raw materials, radical chemistry, and mass spectrometry. $\mathrm{He}$ retired in 2006 . He has been the chairman of abiosus e.V., a non-profit association for the advancement of research on renewable raw materials since 2006 .

\section{Abstract 11 \\ White Biotechnology in Switzerland - Perspectives for a Sustainable Development}

Hans-Peter Meyer ${ }^{a *}$ and Cathy Kroll ${ }^{b}$

aLonza AG, CH-3930 Visp, bSwiss Biotech Association, $\mathrm{CH}-8004$ Zürich

New developments in technology and methods as well as changing ecological and economical conditions have led to a renaissance and rejuvenation of industrial biotechnology. The proportion of products produced by biotechnology is expected to increase over-proportionally.

However, to realise the expectations of society, investors and other stakeholders the biotechnology industry has to accomplish not only enormous structural changes to introduce more and more biological processes into production. There remain additional issues with respect to innovation, regulatory and financing.

This presentation will give a short overview on the current situation of white or industrial biotechnology, its stakeholders and products and will attempt to identify and answer the bottlenecks mentioned above.

However, this presentation also looks into the future. What could be done in Switzerland in the next 20 years? Which products and industries may be of particular interest for this country? What are the burning issues and what are the long-term questions to be tackled? How can we assure the expected and ambitious development of white biotechnology in Switzerland?

To work on the answers the Swiss Biotech Association (SBA), the SGCl Chemie Pharma Schweiz and the Swiss Industrial Biocatalysis Consortium (SIBC) have formed the Swiss Industrial Biotechnology Platform. Using this platform we have been evaluating and will continue to assess threats and opportunities related to industrial biotechnology in a national as well as a European context. 
Hans-Peter Meyer has 14 years R\&D experience in microbial and mammalian cell culture technology and 20 years managerial experience in R\&D, tech transfer, operations and investments. He joined Lonza in 1986 as a bioprocess engineer after spending several years in research at the Universities of Pennsilvania and Lehigh in the US and the ETH Zürich. At Lonza Hans-Peter Meyer has been the head of development and pilot/launch plants, head of R\&D of the biotech sector, and head of microbial technology development. Since 2006 he has been responsible for marketing intelligence which involves technology scouting \& evaluation; business development with a focus in microbial biotechnology. Lonza contact to EuropaBio, CTI, SBA, SIBC etc).

\section{Abstract 12 \\ Biorefinery - The Bridge between Agriculture and Chemistry}

\section{Johann P. M. Sanders}

Agrotechnology and Food Sciences Group, Wageningen

University, Netherlands

Economic factors, such as the increasing cost of oil, connected to the depletion of mineral resources, and environmental considerations, such as the negative impact of $\mathrm{CO}_{2}$ emissions, has led to interest in the use of renewable resources as feedstocks for transportation fuels, energy (heat and electricity) and chemical products. When used in combination with environmentally sound production and processing techniques, the use of biomass can be seen as a sustainable alternative to conventional feedstocks. In the Netherlands a Governmental Committee on Renewable Resources has designed a plan how to substitute $30 \%$ of the Dutch fossil raw materials by biomass by the year 2030 . Obviously a lot of the biomass will have to come from abroad, but strategies to optimize the use of the biomass that is already used every year might limit the additional area to about the size of the Netherlands. Other European countries having lower import volume of biomass at the moment, but more agricultural area available, might solve their biomass availability in other ways.

Production of chemicals could take advantage of the biomass structure in a much better way than the production of fuels or electricity from biomass. The production of chemicals from biomass saves more fossil energy than producing just energy from biomass! This is reflected by sound economic advantages in raw material costs and in investment costs.

To develop technologically sustainable routes, the entire chain of biomass production, i.e. from cultivation and harvest, its (pre)treatment and conversion to products should be considered. Biorefinery opens the way towards the production of bulk chemicals and thereby obtaining the highest value from biomass by knowledge intensive technologies that can be patented.

Several examples will be shown including the fractionation of grass, sugarbeet, Cassava. Some amino acids are very suitable starting materials for highly functionalized petrochemicals. Economical production routes of chemicals from biomass require large-cale substitution of bulk chemicals and connection to current approaches and facilities (process integration) of the petrochemical industries to convert crude oil into chemical building blocks.
Protein will be an abundant 'waste' product from the boost in production of transportation fuels. Ethanol from wheat and corn and biodiesel from rape and palm will supply an additional amount of protein around 100 million tonnes/ year if these biofuels substitute $10 \%$ of the fuel demand.

Genetic modification of plants will increase the potential of biomass to chemicals because of increase of the concentrations of the actually present biochemicals that can serve as precursors for bulkchemicals.

Also it will be addressed that small-scale (pre)processing of the biomass can give advantages over large-scale processing because of lower transportation costs but also because of the opportunity to use process integrations that cannot be used on a large scale. These integrations will yield high efficiencies of energy utilization but can be improved on social or organisational levels.

The biorefinery of biomass will offer new economic opportunities for the agriculture and the chemical industry by the production of a world of chemicals, transportation fuels and energy.

Johan Saunders graduated at the University of Amsterdam in 1973 and obtained his PhD in Molecular Biology in 1977. For his thesis he was awarded the Winkler Prins prize 1976-1980. He started his industrial career with Gist brocades, creating a genetic engineering group. He was project leader for the Shell/Gist brocade project wood to ethanol. From 1993-2001 he was R\&D Director of AVEBE where he directed research on the modification of starch by enzymatic and GMO modification and other agricultural projects. In 2001 he returned to academia in a managerial function at the Wageningen University and Research Center. Since 2003 he has been the Professor of Valorisation of Plant Production Chains and his current research interests involve reducing $\mathrm{CO}_{2}$ production in a cost-effective way by utilising agricultural raw materials.

\section{Abstract 13 \\ Roundtable on Sustainable Biofuels An Initiative of the EPFL Energy Center}

Hans Björn Püttgen

Director Energy Center, EPFL Lausanne

"Ensuring that biofuels deliver on their promise of sustainability"

With their potential to reduce carbon emissions, help solve global warming, and create economic opportunities for rural areas, biofuels can be an important part of the energy mix of the future. But growing crops for biofuels can have negative impacts, including clearing forests for cropland, depleting and polluting soil and water resources, and reducing the amount of land available for food production. How can we ensure that these fuels are truly a friend to the environment and society, and not a foe?

The Energy Center at the Swiss Federal Technical Institute in Lausanne (EPFL) is coordinating a multi-stakeholder effort, the Roundtable on Sustainable Biofuels, to develop draft global standards for sustainable biofuels production and processing. By early 2008, we aim to have draft standards developed in conjunction with non-governmental organizations, companies, governments and inter-governmental groups from all over the world. Our hope is to create 
a tool that consumers, policy-makers, companies, banks, and other actors can use to ensure that biofuels deliver on their promise of sustainability. There is important work already going on in sustainable biofuels standards development, and our aim is to build on this work and create standards that are:

Simple The standards should be accessible by small producers, inexpensive to measure, and easy to explain.

Generic The standards should be applicable to any crop in any country, and allow comparisons across crops and production systems.

Adaptable The standards should be easy to revise to take into account new technologies and their impacts on relative performance of different biofuels.

Efficient We aim to incorporate other standards and certifications to eliminate duplicative reporting and reduce inspection burdens on producers and processors.

All standards development work will be done in an open and transparent way, with ample comment periods according to the ISEAL code of good practice. The Roundtable will gather opinions and feedback through online technology such as the BioEnergy wiki (www.bioenergywiki.net), conference calls, and regional meetings, to ensure that developing countries and disadvantaged groups have a meaningful opportunity to contribute to the elaboration of the standards.

The standards will be developed through four Working Groups, which will be open to any interested stakeholder. The Working Groups will focus on the following areas:

GHG - Greenhouse Gas Lifecycle Efficiency Analysis. This group will recommend methodologies to use to calculate the efficiency of particular production and processing techniques in terms of replacing greenhouse gas emissions as compared to fossil fuels.

ENV - Environmental Impacts. This group will draft minimum criteria for sustainable biofuels regarding their impact on high conservation value areas, soil and water resources, air pollution, and other environmental issues.

SOC - Social Impacts. This group will outline the criteria for labor rights, food security, poverty alleviation, land rights, and other social elements of sustainable biofuels production.

IMP - Implementation. This group will review the recommendations of the other working groups to ensure that the standards are easy to implement and measure so that they are accessible by small-scale and other low-income farmers. They will also make recommendations on future steps for the Roundtable, such as the potential value of independent third party certification. We encourage any interested party to sign up for one or more Working Groups, and to get involved in this process!

Hans B. (Teddy) Püttgen holds the Chaire de Gestion des Systèmes Energétiques (Energy Systems Management) at the EPFL - Swiss Federal Institute of Technology in Lausanne. Upon his arrival at EPFL, in April 2006, he also became the inaugural Director of the Energy Center.

The Energy Center is a university-wide and cross-disciplinary organization with the responsibility of coordinating all R\&D activities on campus related to energy. EPFL has a very broad energy portfolio located within major laboratories in all five major Facultés (Schools), ranging, for example, from electric power production, distribution and end use to controlled fusion, from hydropower generation to photovoltaics, from building technologies to thermal turbo-machinery. The Energy Center also aims to incor- porate R\&D activities related to economics of energy and public policy.

Before arriving at EPFL, Professor Püttgen was Georgia Power Professor and Vice Chair for External Affairs in the School of Electrical and Computer Engineering at the Georgia Institute of Technology. At Georgia Tech, he launched the National Electric Energy Test, Research and Application Center, NEETRAC, and served as its Director and Management Board Chair.

Until his arrival at EPFL, Teddy Pütgen served as Président and CEO of Georgia Tech Lorraine, the European campus of the Georgia Institute of Technology located in Metz, France.

Teddy Püttgen, who is a Senior Member of PES, served as President of the Power Engineering Society of IEEE in 2004 and 2005 and is a member of the Governing Board and the Executive Committee. He is a recipient of the IEEE third millennium medal.

He graduated from the Swiss Federal Institute of Technology in Lausanne with the Ingénieur Diplômé degree in Electrical Engineering. He holds graduate degrees in Business Administration and Management from the University of Lausanne. His PhD, in Electrical Engineering with an emphasis in electric power, is from the University of Florida. $\mathrm{He}$ is a past recipient of the IEEE Award for Outstanding Faculty Advisor and of the ASEE DOW Outstanding Young Faculty award. 